\title{
CHECKLIST DAS MACROALGAS ARRIBADAS CAPTURADAS EM REDE DE ARRASTO PICARÉ NA PRAIA DE PONTA DA ILHA, RECIFE COSTEIRO DA ILHA DE ITAPARICA, MUNICÍPIO DE VERACRUZ, BAHIA.
}

\author{
$\underline{\text { Rosangela dos Santos Nóbrega }}{ }^{1}$; Carlos Wallace do Nascimento Moura ${ }^{2}$ \\ 1. Bolsista PIBIC/CNPq- Af, Graduando em Ciências Biológicas,Universidade \\ Estadual de Feira de Santana, e-mail: rosangelanobrega2010@ hotmail.com \\ 2. Orientador, Departamento de Ciências Biológicas - DCBIO, Universidade \\ Estadual de Feira de Santana, e-mail: carloswnmoura@hotmail.com
}

PALAVRAS-CHAVE: Inventário taxonômico, Baía de Todos os Santos, Arribada

\section{INTRODUÇÃO}

As macroalgas marinhas, representadas pelas algas da divisão Rhodophyta, Ochrophyta e Chlorophyta, vivem fixas em algum tipo de substrato e geralmente apresentam organização morfológica simples e grande complexidade fisiológica (YoneshigueValentin et al. 2006). O aporte de arribadas alóctone se constitui em um importante subsídio de energia e nutrientes para a comunidade de organismos de praias arenosas, já que estudos revelam que a biomassa vegetal (macroalgas e fanerógamas marinhas) que se deposita na zona entremarés é rapidamente incorporada na teia trófica, à medida que é consumida por crustáceos bentônicos (e.g., anfípodas e isópodos), os quais são importantes presas dos demais consumidores (Kirkman \& Kendrick 1997, Dugan et al. 2003, McLachlan\& Brown,2006). Nessa perspectiva, o conhecimento da diversidade macroalgas pode favorecer estratégias de conservação de ecossistemas aquáticos, além de ser essencial para o desenvolvimento de projetos de monitoramento ambiental. Assim, diante da importância ecológica que as arribadas desempenham em praias arenosas, este trabalho teve como objetivo inventariar as macroalgas $\mathrm{e}$ fanerógamas marinhas arribadas da praia de Ponta da Ilha, na Ilha de Itaparica, Bahia.

\section{MATERIAL E MÉTODO}

O objeto do presente estudo corresponde as macroalgas e fanerógamas marinhas arribadas previamente coletadas (Julho a Dezembro de 2013, Março a Dezembro de 2014 e Fevereiro e 2015), na localidade Ponta da Ilha, situada no município de Vera Cruz, Ilha de Itaparica, Baía de Todos os Santos. O material arribado foi coletado com auxílio de uma rede de praia do tipo picaré $(9 \mathrm{~m}$ de comprimento e $1,5 \mathrm{~m}$ de altura; malha de $13 \mathrm{~mm}$ de distância entrenós nas asas e $5 \mathrm{~mm}$ no centro), sendo esta tracionada manualmente por duas pessoas durante a maré de sizígia,e em cada coleta foram realizados cinco arrastos. A triagem dos táxons presentes nos arrastos, bem como a obtenção do peso úmido destes (utilizando balança analítica de precisão) foi realizada no Laboratório de Ficologia da Universidade Estadual de Feira de Santana.

Foram calculados a riqueza global dos táxons (correspondente ao número total de táxons encontrados); a frequência de ocorrência absoluta de cada táxon (total de vezes que cada táxon ocorreu); e a frequência de ocorrência relativa de cada táxon, expressos em percentagem, através da seguinte fórmula: $\mathrm{F}=\mathrm{n} \cdot 100 / \mathrm{N}$, onde $\mathrm{n}$ (= número de coletas em que um táxon foi registrado) e $\mathrm{N}$ (= número total de coletas realizadas). 
A partir do cálculo da frequência de ocorrência relativa, os táxons foram classificados em categorias, segundo Rodrigues (2006): táxons constantes ( $\mathrm{F}>50 \%)$, acessórios $(25<\mathrm{F}<50 \%)$ e acidentais $(\mathrm{F}<25 \%)$.

\section{RESULTADOS E DISCUSSÃO}

Foram identificados 116 táxons nas arribadas da Praia de Ponta da Ilha sendo 113 macroalgas bentônicas (pertencentes aos filos Rhodophyta, Ochrophyta e Chlorophyta) e três fanerógamas (Tracheophyta), distribuídos em 18 ordens, 36 famílias e 59 gêneros.O Filo Rhodophyta apresentou o maior número de táxons (70), correspondendo a $61 \%$ da riqueza florística relativa, seguida por Ochrophyta $19 \%$, Chlorophytae Tracheophyta com 18\% e 2\%, respectivamente (Figura 1).

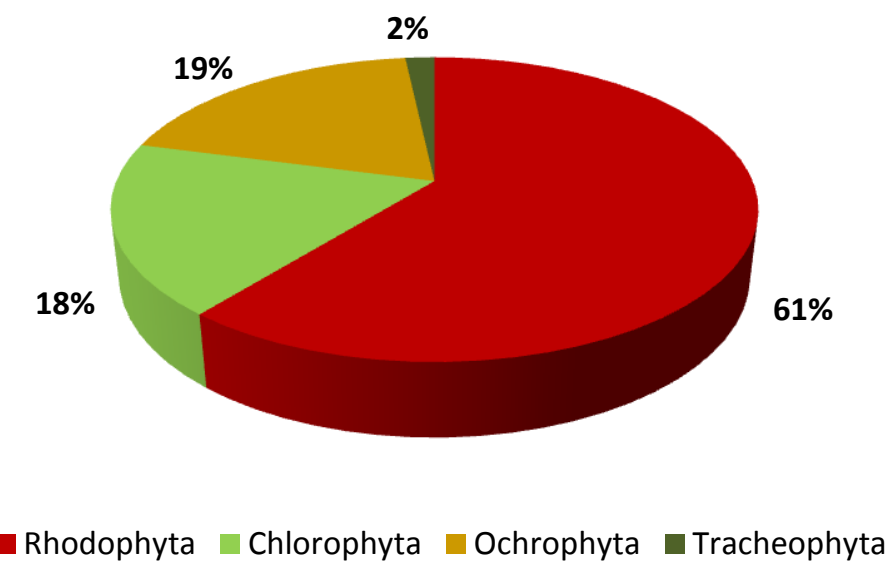

Figura 1. Percentual da riqueza florística das divisões das macroalgas bentônicas e fanerógamasregistradas arribadas na Praia de Ponta da Ilha, na Ilha de Itaparica, Bahia.

Dentre as 18 ordens inventariadas, as mais representativas foram Ceramiales e Gracilariales (Rhodophyta), Bryopsidades, (Chlorophyta) e Dictyotales (Ochrophyta) com 25, 17, 12 e 17 táxons, respectivamente (Figura 2). As famílias mais representativas foram Dictyotaceae e Gracilariaceae com 18 e 17 táxons seguida por Rhodomelaceae e Caulerpaceae com 11 e 10 táxons cada.

O predomínio do Filo Rhodophyta no presente estudo concorda com os resultados obtidos por outros inventários taxonômicos de macroalgas realizados na Baía de Todos os Santos (Marins et al. 2008, Santos 2010, Almeida 2013). Segundo Kain\& Norton (1990), esse padrão é encontrado em floras de regiões tropicais/temperadasquentes, podendo o predomínio das rodófitas ser explicado pela melhor adaptação do grupo à alta turbidez da água, uma vez que apresentam um amplo espectro de absorção da luz, em relação às demais macroalgas (Luning 1990).

A biomassa úmida das macroalgas e fanerógamas marinhas arribadas, capturadas nas redes picaré, na Praia de Ponta da llha durante o período estudado foi alta, tendo os meses de Março de 2013 e Setembro de 2014 os maiores valores em biomassa dominante. 


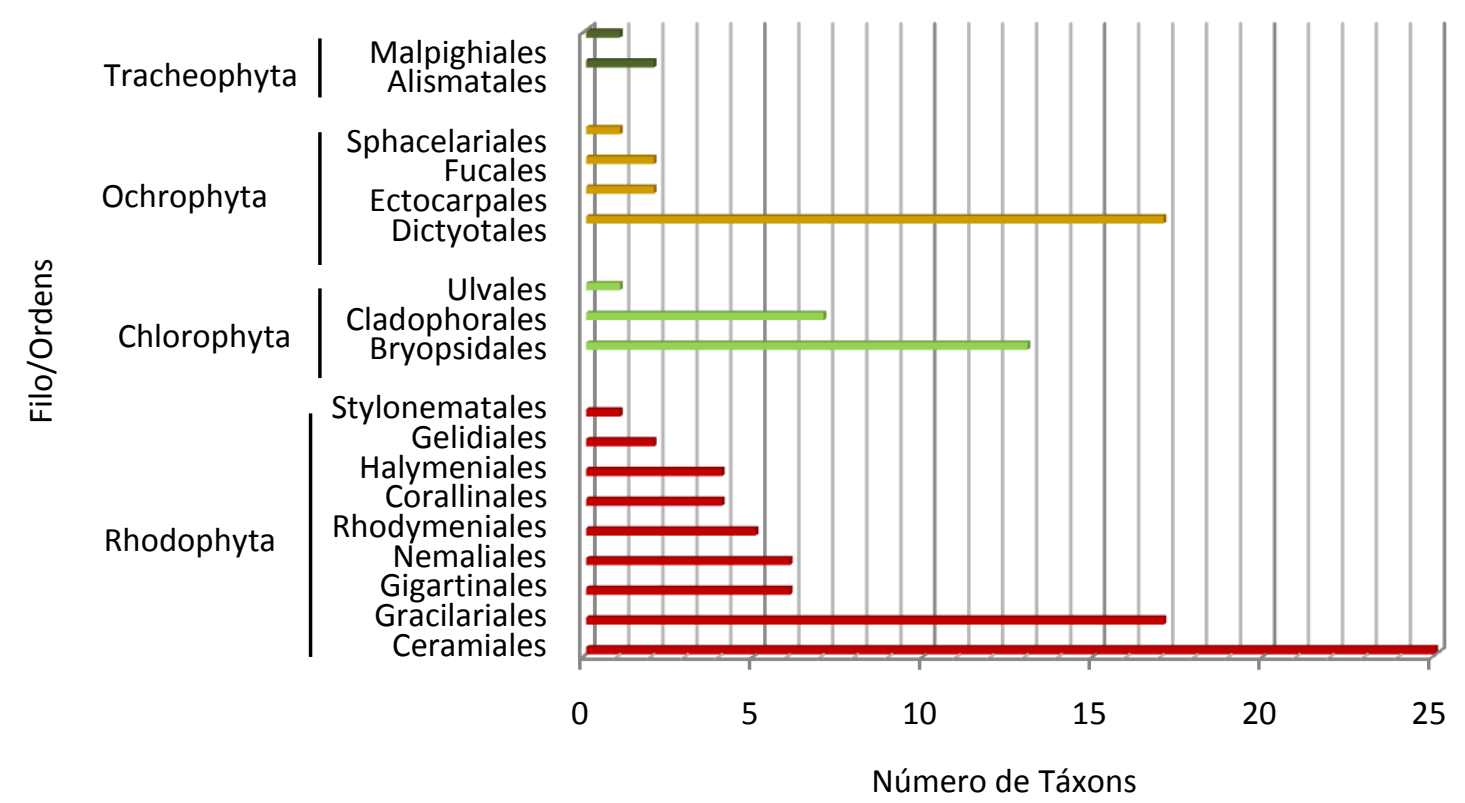

Figura 2. Número de táxons por ordens de Rhodophyta, Ochrophyta, Chlorophyta e Tracheophyta arribados na Praia de Ponta da Ilha, Ilha de Itaparica, Bahia.

A riqueza das macroalgas arribadas da praia da Ponta da Ilha (116 táxons) foi considerada alta e equivalente a referida por Santos et al. (2013) para as praias de Pituba e Itapuã (127 táxons), sendo as arribadas do presente estudo composta em sua maioria por táxons acidentais ( $86 \%$ do total de táxons inventariados).

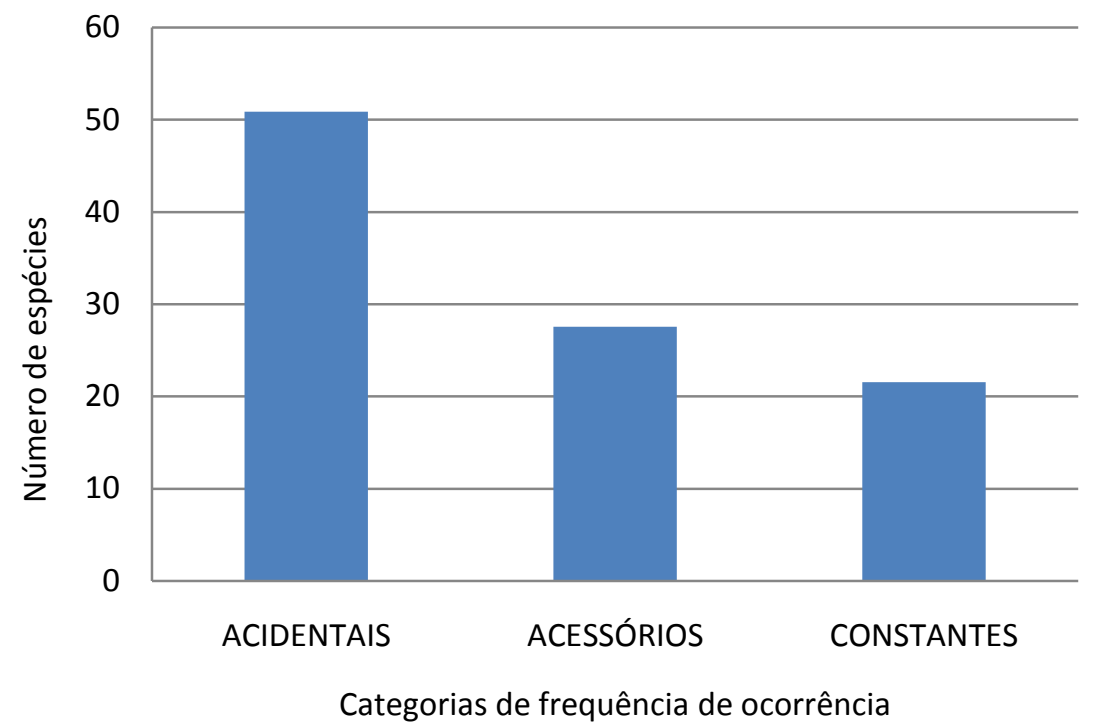

Figura 3. Categorias de frequência de ocorrência dos táxons de macroalgas e fanerógamas arribados na Praia de Ponta da Ilha, Ilha de Itaparica, Bahia.

\section{CONCLUSÕES}

O estudo das arribadas, capturadas em rede picaré, na Praia de Ponta da Ilha revelou a ocorrência de 116 macroalgas bentônicas, pertencentes aos filos Rhodophyta, Ochrophyta e Chlorophyta e três fanerógamas: Halophila decipiens, Halodule wrightiie 
Rhizophora mangle (folha e propágulos). O Filo Rhodophyta apresentou o maior número de táxons de macroalgas (70), correspondendo a $61 \%$ da riqueza florística relativa, seguida por Ochrophyta (22) 19\% e Chlorophyta (21) 18\%.As ordens mais representativas foram Ceramiales e Gracilariales, ambas Rhodophyta,com 25 e 17 táxons, seguidas por Dictyotales (Ochrophyta) e Bryopsidades, (Chlorophyta) com 17 e 12 táxons cada. As arribadas estudadas foram compostas, em sua maioria, por táxons acidentais ( $86 \%$ do total de táxons inventariados), sendo a biomassa úmida dos táxons constantes considerada alta, principalmente nos meses de Março de 2013 e Setembro de 2014.

\section{REFERENCIAS}

Almeida. W.R. 2013. Macroalgas marinhas bentônicas da Ilha Bimbarras, região Norte da Baía de Todos os Santos, Bahia, Brasil. Dissertação de mestrado Universidade Estadual de Feira de Santana. Feira de Santana. 408 p.

Dugan, J.E.; Hubbard, D.M.; McCrary; M.D. \& Pierson, M.O. 2003. The response of macrofauna communities and shorebirds to macrophyte wrack subsidies on exposed sandy beaches of southern California. Estuarine, Coastal and Shelf Science 58S: $25-40$.

Kain, J.M.; Norton, T.A. 1990. Marine Ecology. In: COLE, K.M.; SHEATH, R.G. (eds.) Biology of the red algae. New York: Canbridge University Press. p.: 377-422.

Kirkman, H. \& Kendrick, G.A. 1997. Ecological significance and commercial harvesting of drifting and beachcastmacroalgae and seagrasses in Australia: a review. Journal of Applied Phycology 9: 311-326

Lüning, K. 1990. Seaweeds: their environment, biogeography, and ecophysiology. Revisedtranslation. 527p.

Marins, B.V.; Brasileiro, P.S.; Barreto, M.B.B.; Nunes, J.M.C.; YoneshigueValentin, Y.; Amado-Filho, G.M. 2008. Subtidalbenthic marine algaeofthe Todos os Santos Bay, Bahia State, Brazil. Oecologia brasiliensis, 12(1): 230-243.

McLachlan, A. \& Brown, A.C. 2006. The Ecology of Sandy Shores. 2a ed. Academic Press. 373p.

Santos, A.A. 2010. Comunidades de Macroalgas Epífitas de AcetabulariacrenulataJ.V.Lamour. (Dasycladales, Chlorophyta) das Praias da Penha e Barra Grande, Ilha de Itaparica, Bahia. Dissertação de mestrado - Universidade Estadual de Feira de Santana. Feira de Santana. 276 p.

Santos, G.N.; Nascimento, O.S.; Pedreira, F.A.; Rios, G.I.; Vasconcelos, J.N.; Nunes, J.M.C. 2013. Análise quali-quantitativa das algas arribadas do Norte do estado da Bahia, Brasil. Acta BotanicaMalacitana 38: 13-24

Yoneshigue-Valentin, Y.; Gestinari, L.M.S. \& Fernandes, D.R.P. 2006. Capítulo 2. Macroalgas. In: Lavrado, H.P.; Ignacio, B.L. (eds.) Biodiversidade bentônica da região central da Zona Econômica Exclusiva brasileira Museu Nacional. p.: 67-105. 